\title{
HLA-A24-restricted HTLV-I-specific CTL response reduces the HTLV-I proviral load but the HLA increases the risk of HAM/TSP
}

\author{
Ryuji Kubota ${ }^{1 *}$, Norihiro Takenouchi ${ }^{2}$, Toshio Matsuzaki ${ }^{3}$, Hiroshi Takashima ${ }^{3}$, Shuji Izumo ${ }^{1}$ \\ From 15th International Conference on Human Retroviruses: HTLV and Related Viruses \\ Leuven and Gembloux, Belgium. 5-8 June 2011
}

It is controversial whether HTLV-I-specific CTLs are beneficial or harmful to the host in the development of HAM/TSP. HLA-A2 reduces the risk of HAM/TSP and HLA-A2-restricted HTLV-I Tax11-19-specific CTL response reduces HTLV-I proviral load in asymptomatic HTLV-I carriers (ACs), suggesting that HLA-A2restricted CTLs are beneficial to the host. Recently, HTLV-I Tax301-309 is newly identified as an immunodominant epitope restricted to HLA-A24 and frequency of Tax301-309-specific CTLs is high in HTLV-I-infected individuals. We investigated whether HLA-A24 also reduces the risk of HAM/TSP and compared the differences between HLA-A2- and HLA-A24-restricted Taxspecific CTL responses. We found that the allele frequency of HLA-A24 was significantly increased in HAM/TSP patients compared to ACs. The frequency of HTLV-I Tax301-309-specific CTLs was higher in HAM/ TSP patients than that in ACs and negatively correlated with the HTLV-I proviral load in both HAM/TSP patients and ACs. In the comparison between HLA-A2/ Tax11-19-specific CTLs and HLA-A24/Tax301-309-specific CTLs, the maximum responses by antigen stimulation were not different in IFN-gamma and MIP-1beta productions and CD107a expression, however, the functional avidity of the CTLs was 50 -fold stronger in Tax301-309-specific CTLs than in Tax11-19-specific CTLs. This suggests that Tax301-309-specific CTLs more efficiently recognize HTLV-I-infected cells when the cells express low levels of viral proteins. Our data suggest that HLA-A24 increases the risk of HAM/TSP and that Tax301-309-specific CTLs may play a role in

\footnotetext{
* Correspondence: kubotar@m2.kufm.kagoshima-u.ac.jp

'Center for Chronic Viral Diseases, Kagoshima University, Kagoshima 8908544, Japan

Full list of author information is available at the end of the article
}

the pathogenesis of HAM/TSP even though they reduce the proviral load, or other factors related to HLA-A24 may affect the risk.

\section{Author details}

'Center for Chronic Viral Diseases, Kagoshima University, Kagoshima 8908544, Japan. ${ }^{2}$ Department of Microbiology, Kansai Medical University, Moriguchi, Osaka 570-8506, Japan. ${ }^{3}$ Department of Neurology and Geriatrics, Kagoshima University, Kagoshima 890-8544, Japan.

Published: 6 June 2011

doi:10.1186/1742-4690-8-S1-A113

Cite this article as: Kubota et al:: HLA-A24-restricted HTLV-I-specific CTL response reduces the HTLV-I proviral load but the HLA increases the risk of HAM/TSP. Retrovirology 2011 8(Suppl 1):A113.

Submit your next manuscript to BioMed Central and take full advantage of:

- Convenient online submission

- Thorough peer review

- No space constraints or color figure charges

- Immediate publication on acceptance

- Inclusion in PubMed, CAS, Scopus and Google Scholar

- Research which is freely available for redistribution

Submit your manuscript at www.biomedcentral.com/submit 